\title{
Silodosin in the treatment of benign prostatic hyperplasia
}

This article was published in the following Dove Press journal: Drug Design, Development and Therapy

23 October 2010

Number of times this article has been viewed

\section{Maxime Rossi \\ Thierry Roumeguère}

Department of Urology, Erasme Hospital, University Clinics of

Brussels, ULB, Brussels, Belgium
Correspondence:Thierry Roumeguère Department of Urology, Erasme Hospital, University Clinics of Brussels, ULB, Route de Lennik, 808, 1070 Brussels, Belgium Tel +3225553614

Fax +3225553614

Email thierry.roumeguere@erasme.ulb. ac.be
Abstract: Benign prostatic hyperplasia (BPH)-associated lower urinary tract symptoms (LUTS) are highly prevalent in older men. Medical therapy is the first-line treatment for LUTS due to $\mathrm{BPH}$. Alpha-adrenergic receptor blockers remain one of the mainstays in the treatment of male LUTS and clinical BPH. They exhibit early onset of efficacy with regard to both symptoms and flow rate improvement, and this is clearly demonstrated in placebo-controlled trials with extensions out to five years. These agents have been shown to prevent symptomatic progression of the disease. The aim of this article is to offer a critical review of the current literature on silodosin, formerly known as KMD-3213, a novel alpha-blocker with unprecedented selectivity for $\alpha_{1 \mathrm{~A}}$-adrenergic receptors, as compared with both $\alpha_{1 \mathrm{~B}}$ - and $\alpha_{1 \mathrm{D}}$-adrenoceptors, exceeding the selectivity of all currently used $\alpha_{1}$-blockers, and with clinically promising effects.

Keywords: silodosin, $\alpha_{1 \mathrm{~A}}$ - blockers, lower urinary tract symptoms, benign prostatic hyperplasia, uroselectivity

\section{Introduction}

Benign prostatic hyperplasia (BPH) is a common problem among men after the age of 40 years. The prevalence of BPH increases from approximately $50 \%$ at 60 years to $90 \%$ in men older than 85 years. ${ }^{1-3}$ BPH is the most important cause of lower urinary tract symptoms (LUTS) in males, and $50 \%$ of men with BPH complain of LUTS. ${ }^{2}$ Male LUTS can be classified into three categories, ie, voiding or obstructive (hesitancy, slow stream, intermittency, incomplete emptying), storage or irritative (frequency, urgency, nocturia, urge urinary incontinence), and postmicturition (postvoid dribbling). ${ }^{4}$ These conditions have a significant impact on overall quality of life. ${ }^{5}$

Histologically, BPH develops in the periurethral or transitional zone of the prostate through an increase in the stromal component of the gland, and, to a lesser degree, epithelial cells. ${ }^{1,6}$ This proliferation leads to urethral constriction. The pathogenesis of $\mathrm{BPH}$ is still not well understood, but involves several complicated pathways, including inflammation, apoptosis, and cellular proliferation.?

Treatments for BPH include watchful waiting for mild LUTS, pharmacologic therapies ( $\alpha_{1}$-adrenergic receptor antagonists and/or $5 \alpha$-reductase inhibitors) for moderate to severe LUTS, and surgery for severe LUTS. ${ }^{1}$

Widespread in the lower urinary tract are $\alpha_{1}$-adrenergic receptors (AR). However, three $\alpha_{1}$-AR subtypes $\left(\alpha_{1 \mathrm{~A}}, \alpha_{1 \mathrm{~B}}\right.$, and $\left.\alpha_{1 \mathrm{D}}\right)$ are described in human tissues, ${ }^{8}$ and $\alpha_{1 \mathrm{~A}}$-AR is the main regulator of smooth muscle tone in the bladder neck, prostate, and prostatic urethra. Approximately $75 \%$ of $\alpha_{1}$-AR in the prostate belong to the $\alpha_{1 \mathrm{~A}}$ subtype., ${ }^{9,10}$ Therefore, antagonism of this receptor can lead to an improvement in urinary symptoms 
via relaxation of the lower urinary tract. Moreover, the relief of LUTS mediated by $\alpha$-blockers is mainly explained by antagonism of the $\alpha_{1 \mathrm{~A}}$ subtype. ${ }^{1-13}$

The $\alpha_{1 \mathrm{~B}}$ subtype is widely found in vascular smooth muscle, thus blocking these proteins and causing orthostatic hypotension. ${ }^{14}$ The $\alpha_{1 \mathrm{D}}$ subtype is predominant and functional in human epicardial coronary arteries, and its inhibition might mediate coronary vasodilation. To reduce this cardiovascular side effect, $\alpha_{1}$-AR inhibitors with higher selectivity for the $\alpha_{1 \mathrm{~A}}$ subtype have been developed. ${ }^{15}$ The $\alpha_{1 \mathrm{~A}}$-AR inhibitor, silodosin (KMD-3213; Recordati Spa, Milano, Italy), was approved by the US Food and Drug Administration (FDA) for the treatment of BPH in October 2008. ${ }^{16}$

This paper reviews the literature concerning selectivity, mechanism of action, pharmacokinetics, recommended dosage, clinical efficacy, pharmacologic interactions, and side effects of silodosin for the treatment of BPH.

\section{Methods}

We searched Medline for peer-reviewed articles in the English language supporting the role for silodosin in LUTS. The available clinical studies are presented and discussed. The search terms used were "silodosin", " $\alpha_{1 \mathrm{~A}}$-blocker", "lower urinary tract symptoms", "benign prostatic hypertrophy", and "uroselectivity". The selection of papers was based on relevance.

\section{Selectivity for $\alpha_{I A}$ adrenoceptors}

Prostate contraction is known to be the main contributor to LUTS in BPH, and is predominantly mediated by $\alpha_{1 \mathrm{~A}}$-AR (Table 1). ${ }^{17,18}$ In contrast, all $\alpha_{1}-\mathrm{AR}\left(\alpha_{1 \mathrm{~A}}, \alpha_{1 \mathrm{~B},}, \alpha_{1 \mathrm{D}}\right)$ are implicated in blood vessel contraction. ${ }^{19}$ Consequently, a highly selective $\alpha_{1 \mathrm{~A}}$-AR drug can lead to better treatment and fewer cardiovascular side effects than a nonselective drug. ${ }^{20}$

The quinazoline $\alpha$-AR blockers (alfuzosin, doxazosin, and terazosin) are nonselective drugs with similar affinity for all $\alpha_{1}-\mathrm{AR}$, whereas tamsulosin preferentially blocks $\alpha_{1 \mathrm{~A}}$ and $\alpha_{1 \mathrm{D}}-\mathrm{AR}$, with a 10 -fold greater affinity than for $\alpha_{1 \mathrm{~B}}-\mathrm{AR}$. In contrast, silodosin is highly selective for $\alpha_{1 \mathrm{~A}}-\mathrm{AR}$, with a 162-fold greater affinity than $\alpha_{1 \mathrm{~B}}$-AR and about a 50-fold greater affinity than for $\alpha_{1 \mathrm{D}}-\mathrm{AR}$ (Table 2). ${ }^{21,22}$

The weak cardiovascular effects of silodosin have been demonstrated in many in vivo models. One showed better uroselectivity with silodosin compared with tamsulosin and prazosin in decerebrate dogs. Moreover, this study also showed that the dose required to reduce blood pressure by $20 \%$ was about eight fold greater with silodosin than tamsulosin, and about four fold greater than prazosin after intravenous injection (Table 3). ${ }^{23}$ In another study in dogs, silodosin did not affect blood pressure, heart rate, or electrocardiographic findings at therapeutic doses. ${ }^{24}$

\section{Mechanism of action}

The $\alpha_{1}$-ARs belong to the family of $G$ protein-coupled receptors. Binding of norepinephrine and epinephrine induces phospholipase $\mathrm{C}$ activation, leading to generation of second messengers, including inositol triphosphate and diacylglycerol. Finally, these induce an increase in intracellular calcium levels and smooth muscle contraction. ${ }^{25}$ Consequently, blockage of $\alpha_{1 \mathrm{~A}}$-AR induces prostatic and urethral smooth muscle relaxation, and may improve voiding symptoms. However, silodosin also seems to target afferent nerves in the bladder, and thereby acts on bladder overactivity and storage symptoms. ${ }^{26}$

\section{Pharmacokinetics and recommended dosage}

The silodosin dose recommended by the FDA is $8 \mathrm{mg}$ orally once a day. The drug is absorbed from the gut, and its pharmacokinetic parameters, ie, peak plasma concentration $\left(\mathrm{C}_{\max }\right)$ and area under the plasma concentration versus time curve (AUC) increase linearly with dose. ${ }^{16,27}$

The bioavailability of silodosin is nearly $32 \%$, with a distribution volume of $49.5 \mathrm{~L}$, and the drug is $97 \%$ bound to plasma proteins. ${ }^{28}$ Time to peak concentration of silodosin occurs at approximately 2.6 hours after drug intake. ${ }^{16}$

It has been shown that food is involved in the pharmacokinetic pathway of the drug. Thus, $\mathrm{AUC}$ and $\mathrm{C}_{\max }$ decrease by $4 \%$ to $49 \%$ and by $18 \%$ to $43 \%$, respectively, with a moderate calorie/fat meal. Moreover, food intake delays time to $\mathrm{C}_{\max }$ by about one hour. Therefore, the FDA recommends drug intake with meals, ideally in the morning to avoid the potential side effects associated with high plasma drug concentrations. ${ }^{16,27-29}$

Silodosin undergoes extensive metabolism involving glucuronidation, alcohol aldehyde dehydrogenase, and

Table I $\alpha_{I_{A}}$-adrenoreceptor selectivity of current blockers used to treat lower urinary tract symptoms ${ }^{18}$

\begin{tabular}{llllll}
\hline & Alfuzosin & Doxazosin & Silodosin & Tamsulosin & Terazosin \\
\hline $\begin{array}{l}\alpha_{1} \text {-adrenoreceptor } \\
\text { selectivity }\end{array}$ & Nonsubtype-selective & Nonsubtype-selective & $\alpha_{\mathrm{IA}}>\alpha_{\mathrm{ID}}>\alpha_{\mathrm{IB}}$ & $\alpha_{\mathrm{IA}}=\alpha_{\mathrm{ID}}>\alpha_{\mathrm{IB}}$ & Nonsubtype-selective \\
\hline
\end{tabular}


Table 2 Dissociation constant $\left(\mathrm{K}_{\mathrm{i}}\right)$ and selectivity of silodosin and tamsulosin ${ }^{21}$

\begin{tabular}{|c|c|c|c|c|c|}
\hline & \multicolumn{3}{|l|}{$K_{i}(n M)$} & \multicolumn{2}{|c|}{$\begin{array}{l}\text { AR subtype selectivity } \\
\text { ratio }\end{array}$} \\
\hline & $\alpha_{I A}-A R$ & $\alpha_{1 B}-A R$ & $\alpha_{1 D^{-A R}}$ & $\alpha_{I A} / \alpha_{I B}$ & $\alpha_{I A} / \alpha_{I D}$ \\
\hline Silodosin & $0.036(0.010)$ & $21(5)$ & $2.0(0.4)$ & 583 & 56 \\
\hline Tamsulosin & $0.019(0.002)$ & $0.29(0.02)$ & $0.063(0.011)$ & 15 & 3 \\
\hline
\end{tabular}

Abbreviations: AR, $\alpha$-adrenoreceptor.

oxidative pathways involving cytochrome P450 (CYP)3A4. The main metabolite in plasma is KMD-3213G. This metabolite is generated via the glucuronidation pathway. This glucuronide conjugate has been found to have a half-life of about 24 hours as compared with 13.3 hours for silodosin and an AUC three- or four fold higher than for the parent compound. Therefore, silodosin and its active metabolite have an extended half-life that makes once-daily dosing possible. ${ }^{28-30}$ Silodosin is excreted in the urine $(33.5 \%)$ and feces $(54.9 \%) .{ }^{16}$

Because the prevalence of BPH increases steeply with age, the pharmacokinetics of silodosin have been studied in elderly men (mean age 69 years) compared with young men (mean age 24 years). ${ }^{16}$ Both populations had kidney function within normally accepted limits for age. ${ }^{16}$ The AUC and elimination half-life of silodosin in elderly patients were about $15 \%$ and about $20 \%$ higher, respectively, than values in younger subjects. Moreover, no difference in silodosin $\mathrm{C}_{\max }$ was observed between the two groups, ${ }^{16}$ showing that the pharmacokinetic profile of silodosin does not change in elderly patients as compared with younger patients. Therefore, the standard silodosin dose of $8 \mathrm{mg}$ once daily can be used in elderly patients without any titration.

A study was conducted in six patients with moderate renal impairment (creatinine clearance $30-50 \mathrm{~mL} / \mathrm{min}$ ) and seven patients with normal renal function. The results showed that the $\mathrm{AUC}, \mathrm{C}_{\max }$, and elimination half-life of silodosin were 3.2-, 3.1-, and 2.0-fold greater in patients with moderate renal impairment than in controls. Therefore, a starting dose of

Table 3 Uroselectivity of $\alpha_{1}$-blockers in decerebrate dogs ${ }^{23}$

\begin{tabular}{llll}
\hline $\begin{array}{l}\text { Intravenous } \\
\text { injection }\end{array}$ & $\begin{array}{l}\text { Urethral } \\
\text { pressure } \\
\left.\mathbf{I D}_{\mathbf{5 0}}, \mu \mathbf{g} / \mathbf{k g}\right)\end{array}$ & $\begin{array}{l}\text { Blood } \\
\text { pressure } \\
\left.\mathbf{( E D}_{\mathbf{2 0}}, \mu \mathbf{g} / \mathbf{k g}\right)\end{array}$ & $\begin{array}{l}\text { Uroselectivity } \\
\text { (BP/UP) }\end{array}$ \\
\hline Silodosin & 3.15 & 8.03 & 2.55 \\
Tamsulosin & 1.73 & 0.59 & 0.35 \\
Prazosin & 11.8 & 2.46 & 0.21 \\
\hline
\end{tabular}

Abbreviations: $\mathrm{ID}_{50}$, dose required to inhibit increase in intraurethral pressure by $50 \%$; $\mathrm{ED}_{20}$, dose required to reduce blood pressure by $20 \%$; $\mathrm{BP}$, blood pressure; UP, urethral pressure. one $4 \mathrm{mg}$ capsule daily is required in patients with a creatinine clearance of $30-50 \mathrm{~mL} / \mathrm{min}$ and uptitration is needed after one week. When creatinine clearance is $>50 \mathrm{~mL} / \mathrm{min}$, no adjustment is needed. Silodosin use is contraindicated in patients with severe renal impairment (creatinine clearance $<30 \mathrm{~mL} / \mathrm{min}) .{ }^{16,28}$

With regard to hepatic impairment, a study comparing nine patients with moderate hepatic impairment (Child-Pugh score 7-9) and nine subjects with normal hepatic function showed no difference in the pharmacokinetic profile of silodosin. ${ }^{16}$ The FDA recommendations are that no dose adjustment is necessary in mild-to-moderate hepatic impairment (Child-Pugh score 5-9) and that silodosin is contraindicated in severe impairment (Child-Pugh score >10). ${ }^{16,28}$

\section{Clinical efficacy}

We reviewed the clinical efficacy of silodosin for the treatment of LUTS/BPH using five clinical studies conducted in Japan and the US. The Japanese research was done by Kawabe et al, ${ }^{31}$ and comprised a 12 -week, multicenter $(\mathrm{n}=88$ ) randomized, double-blind, placebo-controlled trial. In total, 457 patients were enrolled, and after randomization received silodosin $8 \mathrm{mg} /$ day $(\mathrm{n}=176)$, tamsulosin $0.2 \mathrm{mg}$ / day $(n=192)$, or placebo $(n=89)$. It must be mentioned that tamsulosin was used at half and even quarter of the dosage ( $0.4 \mathrm{mg}$ once or twice per day) recommended by American Urological Association guidelines for the management of $\mathrm{BPH} .^{32}$

The main inclusion criteria were men aged $\geq 50$ years with an International Prostate Symptom Score (IPSS) $>8$, quality of life (QoL) score $>3$, prostate volume $>20 \mathrm{~mL}$, maximum urinary flow rate $\left(\mathrm{Q}_{\max }\right)<15 \mathrm{~mL} / \mathrm{sec}$, voided volume $>100 \mathrm{~mL}$, and postvoid residual urine volume $<100 \mathrm{~mL}^{31}$ The IPSS is scored from 0 to 35 $(0-7=$ mild, $8-19=$ moderate, $20-35=$ severe $)$ and QoL is scored from 0 (delighted) to 6 (terrible).

The primary endpoint of the trial was the total IPSS change from baseline, and secondary endpoints were change in $\mathrm{Q}_{\max }$, QoL score, and IPSS voiding and storage scores. ${ }^{31}$ Mean change (standard deviation) in total IPSS 
from baseline was $-8.3(6.4),-6.8(5.7)$, and $-5.3(6.7)$ in the silodosin, tamsulosin, and placebo groups, respectively (see Table 4). For QoL score, the change from baseline was -1.7 (1.4), $-1.4(1.3)$, and -1.1 (1.2) in the silodosin, tamsulosin, and placebo groups, respectively. Therefore, silodosin was significantly better than placebo in terms of IPSS and QoL scores $(P<0.001$ and $P=0.002$, respectively). The silodosin IPSS improvement effect (compared with placebo) became apparent at week 1 and was sustained throughout the 12-week study period. At week 2, silodosin was significantly better than tamsulosin in IPSS improvement $(P=0.011)$ but this effect was not sustained throughout the trial. Thus, as compared with tamsulosin, silodosin showed no significant difference concerning IPSS and QoL scores. All three groups showed improvement in $\mathrm{Q}_{\max }$, with a change from baseline of 2.24 (3.96), 2.95 (4.64), and $2.42(5.50) \mathrm{mL} / \mathrm{sec}$ in the silodosin, tamsulosin, and placebo groups, respectively. However, there was no significant difference between the groups. ${ }^{31}$ IPSS voiding symptoms were significantly improved in the silodosin group compared with the other two groups $(P<0.001$ versus placebo, $P=0.023$ versus tamsulosin). For storage symptoms, improvement by silodosin was statistically significant compared with that on placebo $(P<0.006)$, but no significant difference was recorded for tamsulosin $(P=0.106)$.

Two pivotal Phase III US trials of 12 weeks' duration are presented in the silodosin prescribing information, and have been published in a pooled analysis. ${ }^{16,33}$ This pooled analysis was followed by a nine-month openlabel extension study. ${ }^{34}$ Both studies randomized 457 and 466 patients, respectively, to receive placebo or silodosin $8 \mathrm{mg} /$ day. ${ }^{33}$ The main inclusion criteria were men aged $\geq 50$ years with an IPSS $>13, \mathrm{Q}_{\max } 4-15 \mathrm{~mL} / \mathrm{sec}$, minimum voided volume $\geq 125 \mathrm{~mL}$, and postvoid residual urine volume $<250 \mathrm{~mL}^{33}$

The primary endpoint of the trial was the total IPSS change from baseline and secondary endpoints were change in $\mathrm{Q}_{\max }$ and in IPSS voiding and storage scores. ${ }^{33}$ After 3-4 days of treatment, the improvement in total IPSS from baseline was significantly greater $(P<0.001)$ in the pooled silodosin group $(-4.2[5.26])$ than in the pooled placebo

Table 4 Results of pivotal Phase III clinical trials

\begin{tabular}{|c|c|c|c|c|c|}
\hline \multirow[t]{2}{*}{ Study } & \multirow[t]{2}{*}{ Patients (n) } & \multicolumn{2}{|c|}{ IPSS, mean (SD) } & \multicolumn{2}{|c|}{$\mathbf{Q}_{\max }$, mean (SD), mL/sec } \\
\hline & & Baseline & Change & Baseline & Change \\
\hline \multicolumn{6}{|l|}{ Kawabe et $\mathrm{al}^{31}$} \\
\hline Silodosin 8 mg/day & 175 & I7.I (5.7) & $-8.3(6.4) \square$ & $9.88(2.75)$ & $\mathrm{I} .70(3.3 \mathrm{I})$ \\
\hline Tamsulosin $0.2 \mathrm{mg} /$ day & 192 & $17.0(5.7)$ & $-6.8(5.7) \quad *$ & $9.4 I(2.8 I)$ & $2.60(3.98)$ \\
\hline Placebo & 89 & $17.1(6.1)$ & $-5.3(6.7)-$ & $10.18(2.72)$ & $0.26(2.21)$ \\
\hline \multicolumn{6}{|l|}{ Marks et $\mathrm{al}^{33}$ (Pooled US studies) } \\
\hline Silodosin 8 mg/day & 466 & $21.3(5.1)$ & $-6.4(6.63) \square$ & $8.7(2.60)$ & $2.6(4.43) 7$ \\
\hline Placebo & 457 & $21.3(4.9)$ & $-3.5(5.84) \_*$ & $8.9(2.80)$ & $1.5(4.36)]^{*}$ \\
\hline Marks et $\mathrm{al}^{34}$ (Open-label study) & \multicolumn{5}{|c|}{ 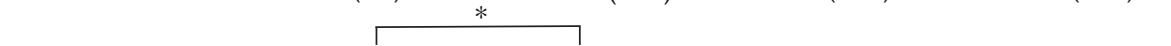 } \\
\hline De novo treatment & 347 & $17.8(6.9)$ & $-4.5(6.7)$ & NS & NS \\
\hline Continuing treatment & 314 & $14.5(7.1)$ & $-1.6(6.0)$ & NS & NS \\
\hline \multirow[t]{2}{*}{ Study } & \multirow[t]{2}{*}{ Patients (n) } & \multicolumn{2}{|c|}{$\begin{array}{l}\text { IPSS voiding symptoms, } \\
\text { mean (SD) }\end{array}$} & \multicolumn{2}{|c|}{$\begin{array}{l}\text { IPSS storage symptoms } \\
\text { mean (SD) }\end{array}$} \\
\hline & & Baseline & Change & Baseline & Change \\
\hline \multicolumn{6}{|l|}{ Kawabe et $\mathrm{al}^{31}$} \\
\hline Silodosin 8 mg/day & 175 & $10.8(4.1)$ & $-5.8(4.6) \square$ & $6.4(3.0)$ & $-2.5(2.9) \sqsupset$ \\
\hline Tamsulosin $0.2 \mathrm{mg} / \mathrm{day}$ & 192 & $10.8(4.2)$ & $-4.8(4.1)]^{*} *$ & $6.2(2.9)$ & $-2.1(2.6)$ \\
\hline Placebo & 89 & $10.9(4.4)$ & $-3.8(4.8) \square$ & $6.3(2.8)$ & $-I .5(2.6)]$ \\
\hline \multicolumn{6}{|l|}{ Marks et $\mathrm{al}^{33}$ (Pooled US studies) } \\
\hline Silodosin 8 mg/day & 466 & $12(3.6)$ & $-4.0(4.31)$ & $9.3(2.6)$ & $-2.3(2.93)-$ \\
\hline Placebo & 457 & $12(3.5)$ & $-2.1(3.76){ }^{*}$ & $9.3(2.5)$ & $-1.4(2.99)-$ \\
\hline \multicolumn{2}{|l|}{ Marks et $\mathrm{al}^{34}$ (Open-label study) } & \multicolumn{2}{|r|}{ - } & \multicolumn{2}{|r|}{ 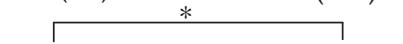 } \\
\hline De novo treatment & 347 & $9.9(4.5)$ & $2.8(4.2)$ & $7.9(3.2)$ & $-1.7(3.2)$ \\
\hline \multirow[t]{2}{*}{ Continuing treatment } & 314 & $7.6(4.5)$ & $-1.0(3.9)$ & 6.9 (3.3) & $-0.6(2.8)$ \\
\hline & & \multicolumn{2}{|r|}{ 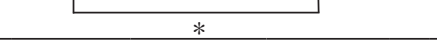 } & \multicolumn{2}{|l|}{ L } \\
\hline
\end{tabular}

Note: $* P<0.07$.

Abbreviations: NS, not studied; SD, standard deviation; IPSS, International Prostate Symptom Score; $Q_{\max }$, maximum urinary flow rate. 
group (-2.3 [4.37]). This significant decrease was sustained throughout the 12-week study ( -6.4 [6.63] versus -3.5 [5.84], $P<0.001)$. Moreover, a significant increase in $\mathrm{Q}_{\max }$ from baseline occurred $2-6$ hours after the first dose $(P<0.001)$ in the pooled silodosin group $(2.8[3.44] \mathrm{mL} / \mathrm{sec})$ compared with the pooled placebo group $(1.5[3.76] \mathrm{mL} / \mathrm{sec})$. Differences remained significant through to week 12 (2.6 [4.43] versus $1.5[4.36] \mathrm{mL} / \mathrm{sec}, P<0.001)$. Irritative/storage symptoms decreased significantly in the pooled silodosin group from the first postbaseline assessment throughout the study $(P<0.001$ for each subscore compared with the pooled placebo group, Table 4). ${ }^{33}$

In total, 661 patients from the pooled study were invited to participate in an open-label nine-month extension study to evaluate the long-term safety and efficacy of chronic dosing with silodosin (Table 4). ${ }^{34}$ Of the patients enrolled in this study, 347 received silodosin for the first time (de novo treatment group) and 314 subjects continued treatment with silodosin (continuing treatment group). ${ }^{33}$ The continuing treatment group had lower baseline IPSS values than the de novo treatment group at the beginning of the nine-month study. At the end of the study, the IPSS irritative/storage subscores showed a significant decrease from baseline in both groups $(P<0.01)$. The total IPSS change from baseline was $-4.5(6.7)$ for de novo treatment and $-1.6(6.0)$ for continuing treatment through to week $40(P<0.01$ for both values compared with baseline). ${ }^{34}$

\section{Pharmacologic interactions}

Because silodosin is metabolized via the CYP3A4 pathway, it is contraindicated in patients taking strong CYP3A4 inhibitors, including clarithromycin, itraconazole, ketoconazole, and ritonavir. These drugs increase the serum concentration of silodosin and the potential risk of side effects by slowing or inhibiting the silodosin metabolism. It has been shown that silodosin $8 \mathrm{mg}$ coadministered with ketoconazole $400 \mathrm{mg}$ increases the $\mathrm{C}_{\max }$ and AUC of silodosin by 3.8- and 3.2-fold, respectively. ${ }^{16}$ Caution is needed when silodosin is used concurrently with moderate CYP3A4 inhibitors, although potential interactions have not been studied. Silodosin can be coadministered with phosphodiesterase type 5 inhibitors. Indeed, a placebo-controlled, open-label crossover study showed minimal reductions in systolic and/ or diastolic blood pressure after coadministration of silodosin with phosphodiesterase type 5 inhibitors (sildenafil $100 \mathrm{mg}$ or tadalafil $20 \mathrm{mg}) .^{35}$

With regard to interaction with antihypertensive agents, there are no studies as yet that have assessed this problem rigorously. However, it is important to note that about one-third of patients enrolled in the US studies were taking antihypertensive agents. ${ }^{33}$ Analysis of the results showed that patient taking antihypertensive agents and silodosin together had more episodes of dizziness than normotensive patients taking silodosin alone (4.6\% versus $3.8 \%$, respectively), as well as a greater frequency of orthostatic hypotension (3.4\% versus $3.2 \%){ }^{33}$ Therefore, careful use and attentive monitoring should be performed, and further clinical studies are mandatory.

\section{Undesirable effects}

Despite its high uroselectivity, silodosin is associated with side effects (summarized in Table 5). In the Japanese and US studies, the most commonly reported adverse reaction was retrograde ejaculation ( $22.3 \%$ and $28.1 \%$, respectively, compared with $1.6 \%$ with tamsulosin and $0 \%-0.9 \%$ with placebo). ${ }^{31,33}$ This adverse event was the main cause of treatment discontinuation of silodosin $(2.8 \%$ and $2.9 \%$, respectively). ${ }^{31,33}$ Retrograde ejaculation is the result of smooth muscle relaxation in the prostate, urethra, bladder neck, and vas deferens. ${ }^{36,37}$ The $\alpha_{1 \mathrm{~A}}$-AR is mainly expressed in the bladder neck, vas deferens, and seminal vesicles. ${ }^{38}$ Moreover, a pharmacologic study showed that the $\alpha_{1 \mathrm{~A}}$-AR subtype mediates human vas deferens contraction. ${ }^{39}$ Thereby, this adverse reaction is explained by the high $\alpha_{1 \mathrm{~A}}$-AR subtype selectivity of silodosin. The other adverse events commonly associated with silodosin were upper respiratory tract infection $(18.9 \%$ versus $27.6 \%$ and $19.1 \%$ with tamsulosin and placebo, respectively), thirst (10.3\% versus $3.6 \%$ and $4.5 \%$ ), loose stools $(9.1 \%$ versus $3.6 \%$ and $5.6 \%)$, urinary incontinence $(6.3 \%$ versus $5.7 \%$ and $0 \%)$, diarrhea $(2.6 \%-6.9 \%$ versus $6.8 \%$ and $5.6 \%$ ), dizziness $(3.2 \%-5.1 \%$ versus $7.3 \%$

Table 5 Adverse effects of silodosin compared with tamsulosin and placebo

\begin{tabular}{llll}
\hline Adverse effects & $\begin{array}{l}\text { Silodosin } \\
(\%)\end{array}$ & $\begin{array}{l}\text { Tamsulosin } \\
(\%)\end{array}$ & $\begin{array}{l}\text { Placebo } \\
\text { (\%) }\end{array}$ \\
\hline $\begin{array}{l}\text { Retrograde } \\
\text { ejaculation }\end{array}$ & $22.3-28.1$ & 1.6 & $0-0.9$ \\
$\begin{array}{l}\text { Upper respiratory } \\
\text { tract infection }\end{array}$ & 18.9 & 27.6 & 19.1 \\
$\begin{array}{l}\text { Thirst } \\
\text { Loose stool }\end{array}$ & 10.3 & 3.6 & 4.5 \\
$\begin{array}{l}\text { Urinary } \\
\text { incontinence }\end{array}$ & 9.1 & 3.6 & 5.6 \\
$\begin{array}{l}\text { Diarrhea } \\
\text { Dizziness }\end{array}$ & 6.3 & 5.7 & 0 \\
Orthostatic & $2.6-6.9$ & 6.8 & 5.6 \\
hypotension & $3.2-5.1$ & 7.3 & 4.5 \\
\hline
\end{tabular}


and $4.5 \%)$ and orthostatic hypotension (2.6\% versus $1.5 \%$ for placebo). ${ }^{31,33}$

The open-label extension study done by Marks et al permitted evaluation of the long-term safety of silodosin. ${ }^{34}$ Retrograde ejaculation occurred more often among patients on de novo treatment than in patients who were continuing treatment (31.1\% versus $9.6 \%$, respectively). Orthostatic hypotension occurred in the same range $(2.9 \%$ versus $2.2 \%$, respectively). More patients receiving de novo treatment $(7.5 \%)$ discontinued the study because of retrograde ejaculation than those continuing treatment (1.9\%). During this extension study, no cardiac disorders and no prolongation of corrected QT interval were found with long-term use of silodosin. ${ }^{35}$

Intraoperative floppy iris syndrome (IFIS) is a complication of cataract surgery observed in patients who have been previously treated with $\alpha_{1}$-blockers, mainly tamsulosin. The clinical manifestations of IFIS are pupil constriction, fluttering, and billowing of the iris stroma, with a propensity of the iris to prolapse during cataract surgery. ${ }^{40} \mathrm{~A}$ prospective study was conducted in 1968 Japanese patients receiving various $\alpha_{1}$-blockers, including silodosin, before cataract surgery. ${ }^{41}$ The overall incidence of IFIS was $1.1 \%$ and, interestingly, no IFIS occurred in patients receiving silodosin. However, one case of IFIS has been reported in a nine-month, open-label, tolerability study of silodosin. ${ }^{16}$ Nevertheless, patients need to inform their ophthalmologist about silodosin use, and it is recommended to stop the medication before cataract surgery is performed.

\section{Conclusion}

Alpha-blockers remain the first-line therapy for LUTS in BPH. Silodosin, a new $\alpha_{1 \mathrm{~A}}$-blocker, has been approved by the FDA since October 2008 at a recommended dose of $8 \mathrm{mg}$ orally once daily. Clinical studies have shown that this selective $\alpha_{1 \mathrm{~A}}-\mathrm{AR}$ is very attractive and more effective than placebo for voiding and storage symptoms in LUTS arising from BPH. Silodosin has excellent early efficacy, and is at least as effective as for other $\alpha_{1}$-blockers. Silodosin distinguishes itself by a strong effect not only on symptoms but also on obstruction as measured by pressure flow studies, a finding perhaps explained by its strong selectivity for $\alpha_{1 \mathrm{~A}}$-AR. At the present time, it is still unknown whether combining silodosin with $5 \alpha$-reductase inhibitors is better than either treatment alone for reducing progression of the disease.

Although silodosin is very attractive, a long-term study comparing this drug with other $\alpha_{1}$-blockers, especially tamsulosin, is needed to help physicians write the right prescription for the treatment of BPH and LUTS in men.

\section{Disclosure}

The authors report no conflicts of interest in this work.

\section{References}

1. AUA Practice Guidelines Committee. AUA guideline on management of benign prostatic hyperplasia (2003). Chapter 1: Diagnosis and treatment recommendations. J Urol. 2003;170:530-547.

2. Wasserman NF. Benign prostatic hyperplasia: A review and ultrasound classification. Radiol Clin North Am. 2006;44:689-710.

3. Thorpe A, Neal D. Benign prostatic hyperplasia. Lancet. 2003;361: 1359-1367.

4. Chapple CR, Roehrborn CG. A shifted paradigm for the further understanding, evaluation, and treatment of lower urinary tract symptoms in men: Focus on the bladder. Eur Urol. 2006;49:651-659.

5. Sountoulides P, van Dijk MM, Wijkstra H, de la Rosette JJ, Michel MC. Role of voiding and storage symptoms for the quality of life before and after treatment in men with voiding dysfunction. World $J$ Urol. 2010;28:3-8.

6. Roehrborn CG, McConnell JD. Benign prostatic hyperplasia: Etiology, pathophysiology, epidemiology, and natural history. In: Wein AJ, Kavoussi LR, Novick AC, et al, editors. Campbell-Walsh Urology. 9th ed. Philadelphia, PA: WB Saunders; 2007.

7. Descazeaud A, Rubin MA, Hofer M, et al. BPH gene expression profile associated to prostate gland volume. Diagn Mol Pathol. 2008; 17:207-213.

8. Price DT, Lefkowitz RJ, Caron MG, et al. Localization of mRNA for three distinct alpha 1-adrenergic receptor subtypes in human tissues: Implications for human alpha-adrenergic physiology. Mol Pharmacol. 1994;45:171-175.

9. Moriyama N, Kurimoto S, Horie S, et al. Detection of $\alpha_{1}$-adrenoceptor subtypes in human hypertrophied prostate by in situ hybridization. Histochem J. 1996;28:283-288.

10. Nasu K, Moriyama N, Kawabe K, et al. Quantification and distribution of $\alpha_{1}$-adrenoceptor subtype mRNAs in human prostate: Comparison of benign hypertrophied tissue and non-hypertrophied tissue. $\mathrm{Br} J$ Pharmacol. 1996;119:797-803.

11. Forray C, Bard JA, Wetzel JM, et al. The alpha 1-adrenergic receptor that mediates smooth muscle contraction in human prostate has the pharmacological properties of the cloned human alpha 1c subtype. Mol Pharmacol. 1994;45:703-708.

12. Murata S, Taniguchi T, Takahashi M, et al. Tissue selectivity of KMD-3213, an alpha (1)-adrenoreceptor antagonist, in human prostate and vasculature. J Urol. 2000;164:578-583.

13. Yamagishi R, Akiyama K, Nakamura S, et al. Effect of KMD-3213, an alpha 1A-adrenoceptor-selective antagonist, on the contractions of rabbit prostate and rabbit and rat aorta. Eur J Pharmacol. 1996;315: 73-79.

14. Roehrborn CG, Schwinn DA. $\alpha_{1}$-Adrenergic receptors and their inhibitors in lower urinary tract symptoms and benign prostatic hyperplasia. J Urol. 2004;171:1029-1035.

15. Schwinn DA, Roehrborn CG. Alpha1-adrenoceptor subtypes and lower urinary tract symptoms. Int J Urol. 2008;15:193-199.

16. Rapaflo ${ }^{\circledR}$ (silodosin) [Package insert]. Corona, CA: Watson Pharmaceuticals, Inc; 2009.

17. Michel MC, Vrydag W. Alpha1-, alpha2- and beta-adrenoceptors in the urinary bladder, urethra and prostate. Br J Pharmacol. 2006;147: S88-S119.

18. Roehrborn CG. Efficacy of $\alpha$-adrenergic receptor blockers in the treatment of male lower urinary tract symptoms. Rev Urol. 2009;11 Suppl 1: S1-S8.

19. Guimaraes S, Moura D. Vascular adrenoceptors: An update. Pharmacol Rev. 2001;53:319-356.

20. Beduschi MC, Beduschi R, Oesterling JE. Alpha-blockade therapy for benign prostatic hyperplasia: From a nonselective to a more selective alpha1A-adrenergic antagonist. Urology. 1998;51:861-872. 
21. Shibata K, Foglar R, Horie K, et al. KMD-3213, a novel potent $\alpha_{1 \mathrm{~A}}$-adrenoceptor-selective antagonist: Characterization using recombinant human $\alpha_{1}$-adrenoceptors and native tissues. Mol Pharmacol. 1995;48:250-258.

22. Tatemichi S, Kobayashi K, Maezawa A, et al. $\alpha_{1}$-Adrenoceptor subtype selectivity and organ specificity of silodosin (KMD-3213). Yakugaku Zasshi. 2006;126:209-216.

23. Akiyama K, Noto H, Nishizawa O, et al. Effect of KMD-3213, an $\alpha_{1 \mathrm{~A}}$ adrenoceptor antagonist, on the prostatic urethral pressure and blood pressure in male decerebrate dogs. Int J Urol. 2001;8:177-183.

24. Tatemichi S, Kiguchi S, Kobayashi M, et al. Cardiovascular effects of the selective $\alpha_{1 \mathrm{~A}}$-adrenoceptor antagonist silodosin (KMD-3213), a drug for the treatment of voiding dysfunction. Arzneimittelforschung. 2006;56:682-687.

25. Hawrylyshyn KA, Michelotti GA, Coge F, et al. Update on human alpha1-adrenoceptor subtype signaling and genomic organization. Trends Pharmacol Sci. 2004;25:449-455.

26. Yokoyama O, Ito H, Aoki Y, et al. Selective $\alpha_{1 \mathrm{~A}}$-blocker improves bladder storage function in rats via suppression of $\mathrm{C}$-fiber afferent activity. World J Urol. 2009 Oct 16. [Epub ahead of print].

27. Yoshida M, Homma Y, Kawabe K. Silodosin, a novel selective $\alpha_{1 \mathrm{~A}}$ adrenoceptor selective antagonist for the treatment of benign prostatic hyperplasia. Exp Opin Invest Drugs. 2007;16:1955-1965.

28. Montorsi F. Profile of silodosin. Eur Urol Suppl. 2010;9(4):491-495.

29. Guay DRP. Silodosin: An orally active selective $\alpha_{1}$-adrenoceptor antagonist for benign prostatic hyperplasia. Aging Health. 2009;5:459-473.

30. Matsubara Y, Kanazawa T, KojimaY, et al. Pharmacokinetics and disposition of silodosin (KMD-3213). Yakugaku Zasshi. 2006;126:237-245.

31. Kawabe K, Yoshida M, Homma Y; for the Silodosin Clinical Study Group. Silodosin, a new $\alpha_{1 \mathrm{~A}}$-adrenoceptor-selective antagonist for treating benign prostatic hyperplasia: Results of a phase III randomized, placebo-controlled, double blind study in Japanese men. BJU Int. 2006;98:1019-1024
32. American Urological Association. Results of the treatment outcomes analyses. In: Management of BPH. Available from: http://www.auanet. org/content/guidelines-and-quality-care/clinical-guidelines. Accessed 2010 Sep 15.

33. Marks LS, Gittelman MC, Hill LA, et al. Rapid efficacy of the highly selective $\alpha_{1 \mathrm{~A}}$-adrenoceptor antagonist silodosin in men with signs and symptoms of benign prostatic hyperplasia: Pooled results of 2 phase 3 studies. J Urol. 2009;181:2634-2640.

34. Marks LS, Gittelman MC, Hill LA, et al. Silodosin in the treatment of the signs and symptoms of benign prostatic hyperplasia: A 9-month, open-label extension study. Urology. 2009;74:1318-1322.

35. Macdiarmid SA, Hill LA, Volinn W, et al. Lack of pharmacodynamic interaction of silodosin, a highly selective $\alpha_{1 \mathrm{~A}}$-adrenoceptor antagonist, with the phosphodiesterase- 5 inhibitors sildenafil and tadalafil in healthy men. Urology. 2010;75:520-525.

36. Michel MC. $\alpha_{1}$-Adrenoceptors and ejaculatory function. $B r J$ Pharmacol. 2007;152:289-290.

37. Kobayashi K, Masumori N, Hisasue S, et al. Inhibition of seminal emission is the main cause of an ejaculation induced by a new highly selective $\alpha_{1 \mathrm{~A}}$-blocker in normal volunteers. J Sex Med. 2008;5:2185-2190.

38. Schulman CC. Lower urinary tract symptoms/benign prostatic hyperplasia: Minimizing morbidity caused by treatment. Urology. 2003; 62 Suppl 3A:24-33.

39. Moriyama N, Nasu K, Takeuchi T, et al. Quantification and distribution of $\alpha_{1}$-adrenoceptor subtype in mRNAs in human vas deferens: Comparison with those of epididymal and pelvic portions. Br J Pharmacol. 1997;122:1009-1014.

40. Avisar R, Weinberger D. Intraoperative floppy iris syndrome: Possible relationship with $\alpha_{1}$-adrenergic receptor antagonists. Isr Med Assoc J. 2009;11:42-44.

41. Oshika T, Ohashi Y, Inamura M, et al. Incidence of intraoperative floppy iris syndrome in patients on either systemic or topical $\alpha_{1}$-adrenoceptor antagonist. Am J Ophthalmol. 2007;143:150-151.
Drug Design, Development and Therapy

\section{Publish your work in this journal}

Drug Design, Development and Therapy is an international, peerreviewed open-access journal that spans the spectrum of drug design and development through to clinical applications. Clinical outcomes, patient safety, and programs for the development and effective, safe, and sustained use of medicines are a feature of the journal, which

\section{Dovepress}

has also been accepted for indexing on PubMed Central. The manuscript management system is completely online and includes a very quick and fair peer-review system, which is all easy to use. Visit http://www.dovepress.com/testimonials.php to read real quotes from published authors. 